\title{
The diagnostic accuracies of chronic obstructive pulmonary disease (COPD) in general practice: the results of the MAGIC (Manchester Airways Group Identifying COPD) study
}

\author{
Timothy L. Frank*, Michelle L. Hazell, Mary F. Linehan, Peter I. Frank
}

General Practice Research Unit, North West Lung Research Centre, Wythenshawe Hospital, Manchester, M23 9LT, UK

Received 11 November 2005; accepted 20 July 2006

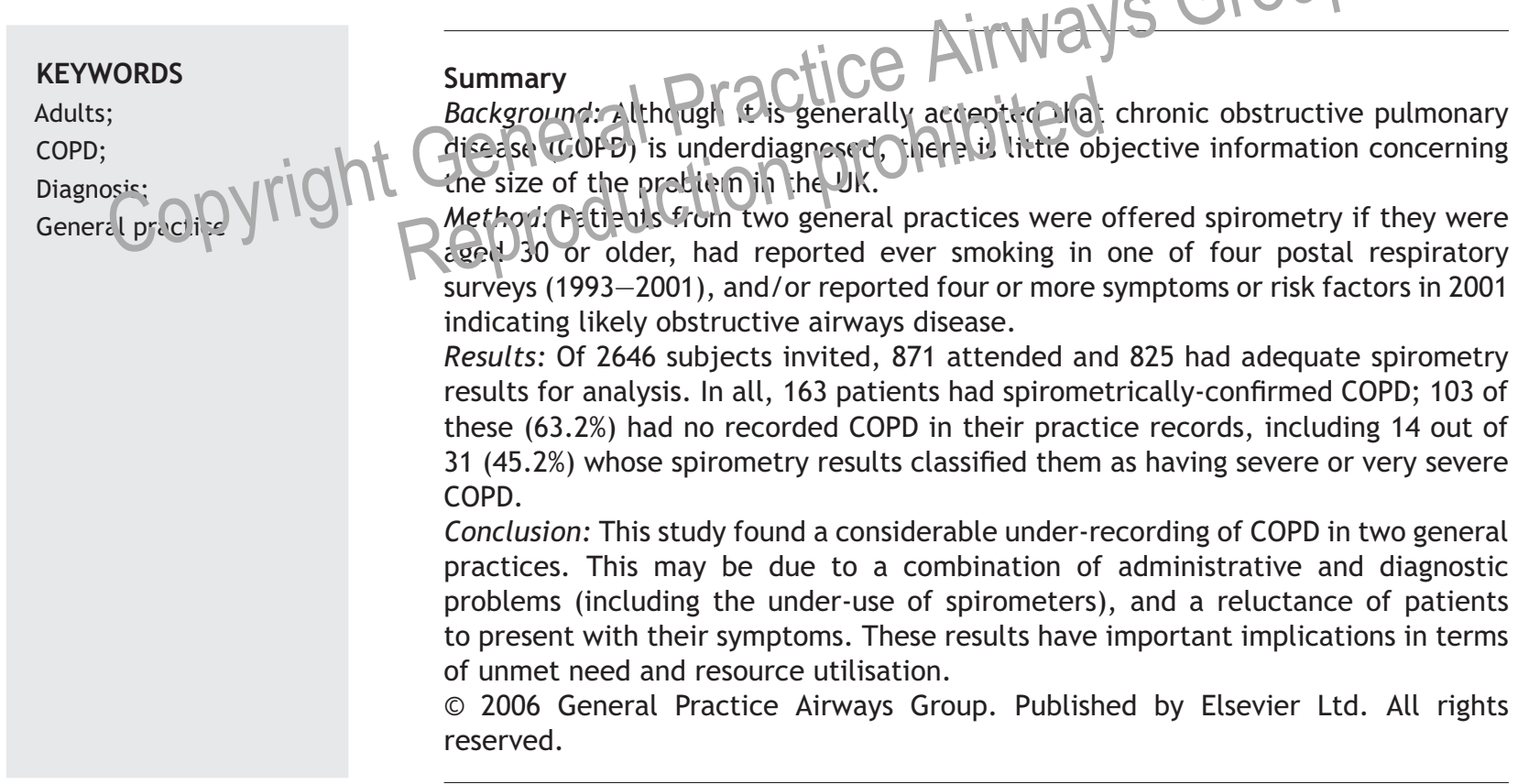

\section{Introduction}

\footnotetext{
* Corresponding author. Tel.: +44 (0) 161291 5044;

fax: +44 (0) 1612915047.

E-mail address: gpresearchunit@yahoo.co.uk (T.L. Frank).
}

Although it is predicted that COPD will be the fifth leading cause of disability and the third leading cause of death in the world in the first half of the 21 st century [1], there is no standard approach 
to the definition of the condition, and diagnosis by lung function testing has used varying criteria [2-5]. It is therefore not surprising that the correct identification of patients with COPD has proved difficult in general practice [6-8].

The principal aims of the MAGIC study (Manchester Airways Group Identifying COPD) were to examine the diagnosis and recording of COPD and to estimate the prevalence of the condition in two general practice populations in an area of South Manchester with high levels of deprivation [9]. This paper is concerned with the accuracy of diagnosis and the recording of COPD in the patients' general practice records.

\section{Method}

The study was part of the Wythenshawe Community Asthma Project (WYCAP), a long term investigation of the natural history of respiratory symptoms in two general practices [10-12] approved by South Manchester Local Research Ethics Committee.

Postal respiratory questionnaire surveys were carried out on four separate occasions, between 1993 and 2001. The questionnaire used for adults was based on the European Community Respiratory Health Questionnaire [13] with add $=d$ questions concerning current smoking, history of hay fever/eczema, and farily hi:tory of asthma
[10]. A simple scoring system was developed and found to be useful in identifying subjects with likely obstructive airways disease (OAD) [14], although it was not used to differentiate COPD from asthma. Those reporting four or more symptoms or risk factors from six key questions (wheezing, being woken by cough, being woken by chest tightness, being woken by shortness of breath - all in the previous 12 months, history of hay fever/eczema, and family history of asthma) were categorised as having OAD.

Figure 1 shows the inclusion criteria for the study. Patients were considered eligible for the present study if they

- replied to the 2001 survey and

- were aged 30 years or more at the time of the 2001 survey and

- responded in any of the four surveys that they were a current smoker and/or reported four or more of the six key symptoms or risk factors (i.e. likely to have OAD) in the 2001 survey.

Over a period of 18 months (Jul 2002 to December 2003) the practice nuses attempted to make cchtact wivin ail eligible patients by tcieplore, by letter if no telephone number was avaitable, or popp pronistically if they consulted at the surgery

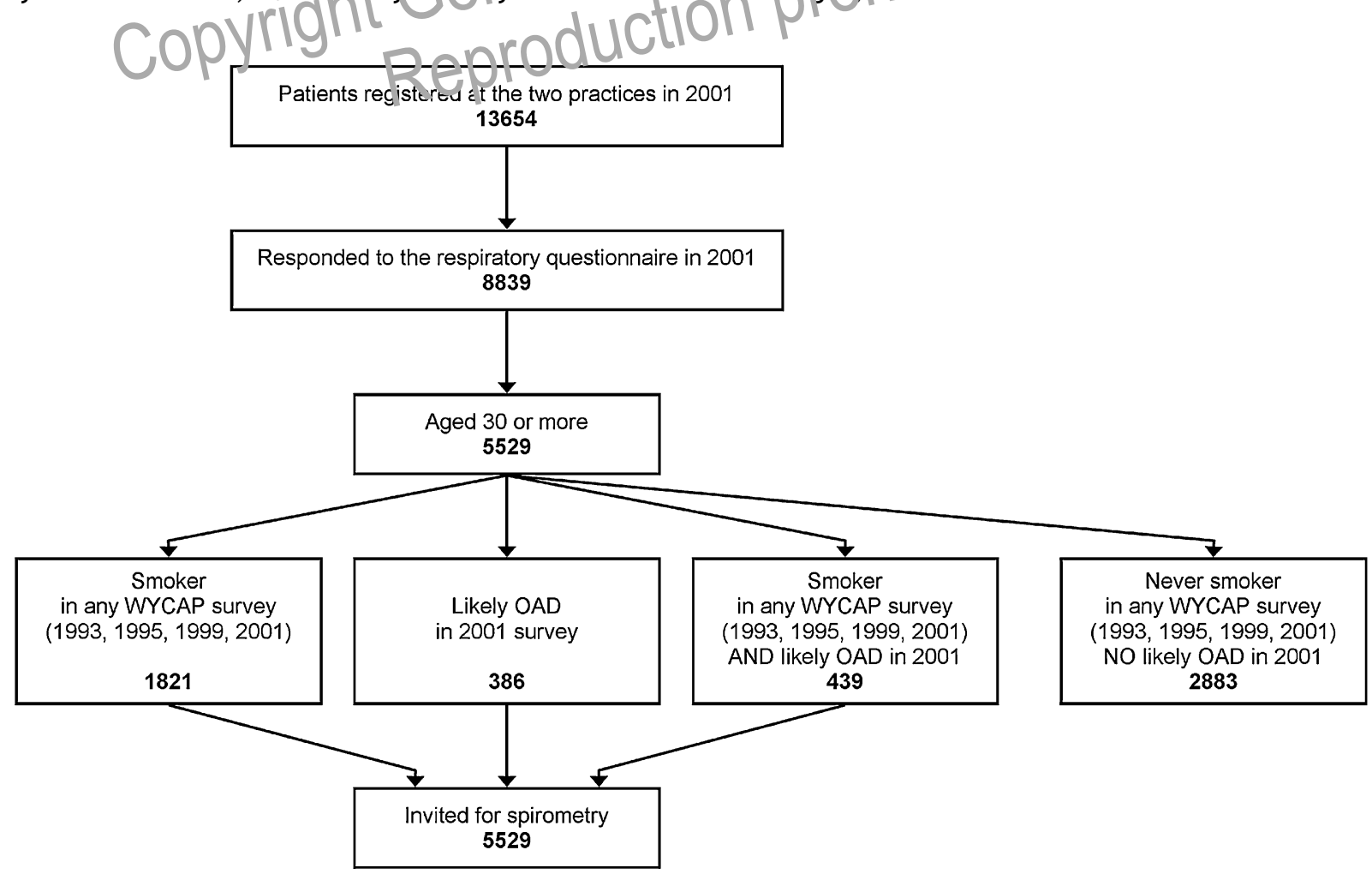

Figure 1 Inclusion criteria. 
Table 1 Characteristics of those included in the analyses compared with those invited but not included due to non-response or inadequate spirometry results

\begin{tabular}{lllll}
\hline & $\begin{array}{l}\text { Successful spirometry } \\
n=825\end{array}$ & $\begin{array}{l}\text { No spirometry } \\
n=1821\end{array}$ & Difference & $\begin{array}{l}95 \% \mathrm{Cl} \text { of } \\
\text { difference }\end{array}$ \\
\hline Mean age (2001) & 55.5 & 50.7 & 4.8 & 3.6 to 6.0 \\
\% female & 54.7 & 52.9 & 1.8 & -2.3 to 5.9 \\
\% ever smokers & 65.2 & 74.9 & -9.7 & -13.5 to -5.9 \\
\% Likely OAD (2001) & 37.2 & 31.4 & 5.8 & 1.9 to 9.7 \\
\hline
\end{tabular}

Patients were invited to attend the surgeries for an interview and for lung function tests, at which point oral informed consent to participate was obtained. The practice nurses, all of whom had received special training in spirometry by a trained lung function technician from the North West Lung Centre, carried out interviews and measurements. As the last postal questionnaire had been completed more than one year before the present study, participants were asked to complete a new respiratory questionnaire similar to those used in the WYCAP surveys with some added questions concerning chronic cough (Appendix A). These new data were used for the present analyses.

Additional smoking history was recorded by direct questioning. Current and ex-smokers were asked about their daily consumption and the number of years they had smoked; smoking his:or ?

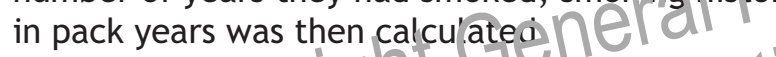

Spirometry was ic arried out using a Microldón

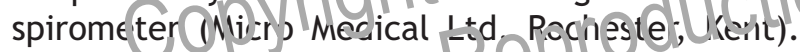
Forced expiratory volume n cine second $\left(\mathrm{FEV}_{1}\right)$, forced vital capacity (FVC) and FEV 1 FVC ratio were measured. Reversibility testing was carried out using salbutamol $400 \mathrm{mcg}$ and ipratropium bromide $80 \mathrm{mcg}$ (combined preparation) via a large volume spacer, with re-testing 20 minutes after inhalation.

The definition of COPD used in this study was based on spirometry results and was in accordance with the 2003 GOLD criteria [5]. Subjects with GOLD stage 2-4 disease were classified as having COPD $\left(\mathrm{FEV}_{1}<80 \%\right.$ of predicted and $\mathrm{FEV}_{1} / \mathrm{FVC}$ ratio $<70 \%$, after bronchodilation).

For all participants, a search was made in the practice computer records for a diagnosis of COPD (ever) or asthma (ever), and for any prescription for inhaled respiratory medications over the previous 12 months.
Differences in means and proportions are presented, along with $95 \%$ confidence intervals of those differences [15]. Trends in proportions were examined for statistical significance using the chisquared test for trend [16].

\section{Results}

In total, 13654 patients were registered with the two practices in 2001. Response rates ranged from $76 \%$ in 1993 to $68 \%$ in 2001 [12]. For the present study, 2646 patients fulfilled the entry riteria and were invited for spirometry (5.g ar e i) In all, 871 (32.9\%) at endec testing, of whom 825 (94.7\%) had result; that were adequate for analysis. Those included were "c!der cind more likely to have been catesorised as having likely OAD in the 2001 survey, bu' hau a significantly lower prevalence of 'ever' smokers (having indicated that they smoked in one of the four surveys) than the remainder of the invited patients (Table 1).

Spirometry results were consistent with a diagnosis of COPD (GOLD stage 2-4) in 163 subjects. COPD increased with age (Table 2) (chisquared $=62.81$ on $5 \mathrm{df}, p$ for trend $<0.001$ ) and it was more frequent in males $(23.5 \%)$ than females (16.6\%) (difference 6.9\%, 95\% confidence interval (Cl) of difference 1.4 to $12.4 \%$ ) (Table 3). COPD was also more frequent in those with a smoking history of more than 20 pack years.

A practice-recorded diagnosis of COPD was also more frequent in older patients (Table 2) (chisquared $=25.04$ on $5 \mathrm{df}, p$ for trend $<0.001$ ), in males, and in those with a smoking history of 20 or more pack years (Table 3 ). There was no mention of COPD in the practice records in 103 of the

Table 2 Number (\%) of subjects with COPD by age in those with adequate spirometry

\begin{tabular}{lccccccc}
\hline & $30-39$ & $40-49$ & $50-59$ & $60-69$ & $70-79$ & $80+$ & Total \\
\hline Screened population & 103 & 172 & 241 & 167 & 119 & 23 & 825 \\
COPD by spirometry & $1(1.0)$ & $20(11.6)$ & $38(15.8)$ & $54(32.3)$ & $44(37.0)$ & $6(26.1)$ & 163 \\
Recorded diagnosis & $1(1.0)$ & $7(4.1)$ & $12(5.0)$ & $19(11.4)$ & $17(14.3)$ & $4(17.4)$ & 60 \\
\hline
\end{tabular}




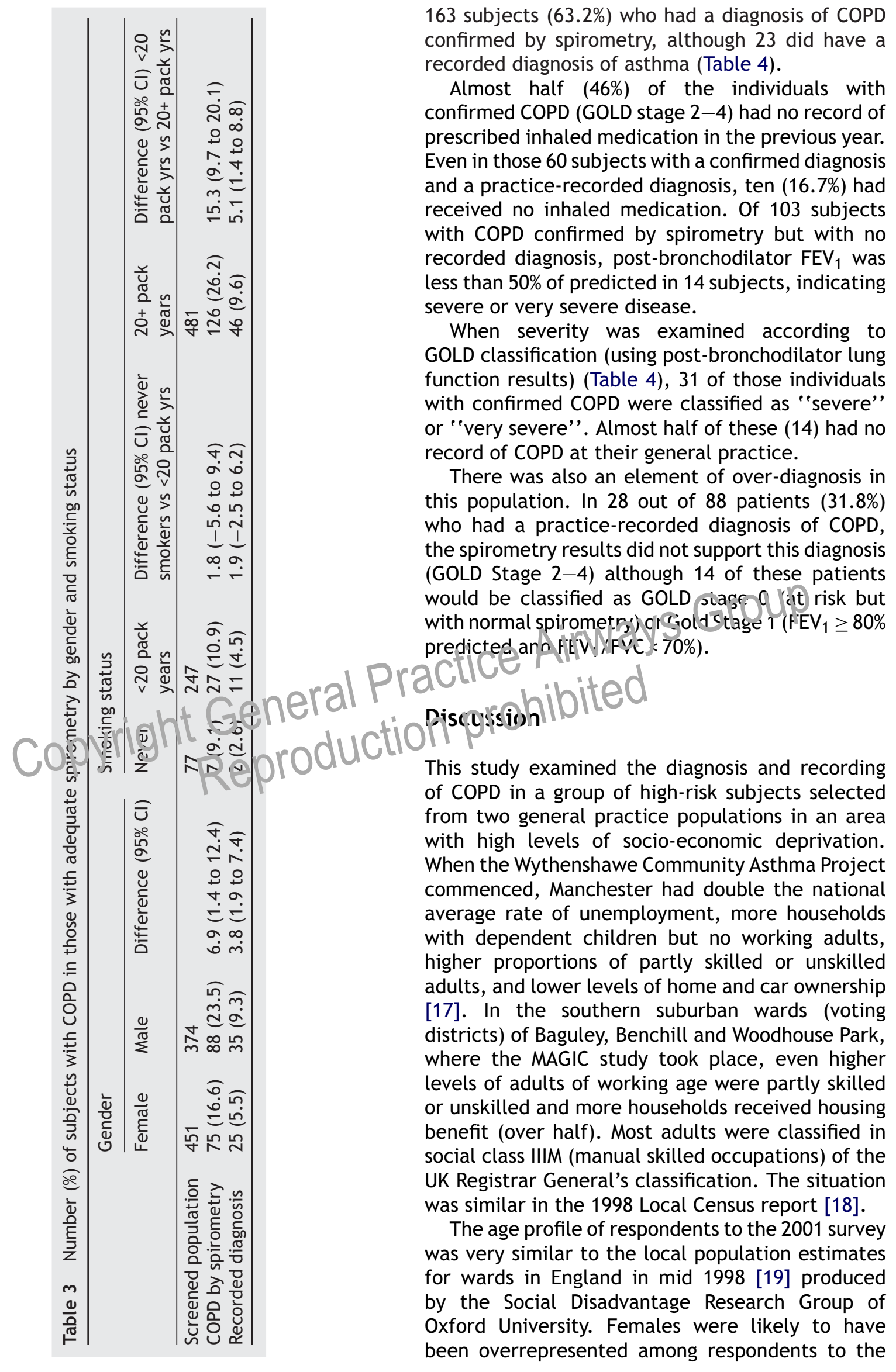


Table 4 Number of subjects by GOLD classification of COPD and recorded diagnosis in practice records in those with adequate spirometry

\begin{tabular}{|c|c|c|c|c|c|c|}
\hline & \multicolumn{6}{|l|}{ GOLD stage } \\
\hline & Not at risk & 0 At risk & 1 Mild & 2 Moderate & 3 Severe & 4 Very severe \\
\hline $\mathrm{FEV}_{1} \%$ predicted & $\geq 80 \%$ & $\geq 80 \%$ & $\geq 80 \%$ & $\geq 50 \%$ but $<80 \%$ & $\geq 30 \%$ but $<50 \%$ & $<30 \%$ \\
\hline $\mathrm{FEV}_{1} / \mathrm{FVC}$ & $\geq 70 \%$ & $\geq 70 \%$ & $<70 \%$ & $<70 \%$ & $<70 \%$ & $<70 \%$ \\
\hline Chronic symptoms & yes & no & - & - & - & - \\
\hline No recorded diagnosis & 466 & 57 & 13 & 69 & 10 & 1 \\
\hline Asthma only & 82 & 10 & 6 & 20 & 2 & 1 \\
\hline $\begin{array}{l}\text { COPD only or COPD } \\
\text { and asthma }\end{array}$ & 14 & 9 & 5 & 43 & 15 & 2 \\
\hline Total & $n=562$ & $n=76$ & $n=24$ & $n=132$ & $n=27$ & $n=4$ \\
\hline
\end{tabular}

2001 survey compared with the population as a whole.

Spirometry results suggested that $20 \%$ of these subjects had COPD, of whom 19\% would be categorised as "severe" or "very severe" by GOLD criteria [5]. $63 \%$ of the patients with spirometrically-defined COPD had no mention of the condition in their practice records; even amongst those whose spirometry showed severe or very severe disease, COPD was not recorded in $48.5 \%$ of cases.

Possible factors causing the discrepancy between spirometrically-defined $\mathrm{CONO}^{-}$and the recording of the conldition ir these patients' general practice referds could include: ncp red or non-diagricisis by the cortars; acininisurative failure to record the diagnosed condition correctly; a reluctance of patients to report symptoms; and the under-use of spirometry. A lack of access to spirometers prior to the study may also have affected the correct diagnosis of COPD, although this deficiency has since been corrected in these practices.

Some individuals with COPD could have been wrongly diagnosed as having asthma and will therefore be treated according to a different set of guidelines and possibly given inhaled medication without an appropriate diagnosis [20]. Distinguishing between asthma and COPD remains difficult in primary care and recent advice that reversibility testing is not routinely necessary [21] has made that task harder. Rigid spirometric criteria made it easier to fit a patient into a diagnostic label even though these labels may have been incorrect. However, the impact of this change in policy is as yet undetermined.

This study used an unconventional approach to screen people for COPD by including those who screened positively for $O A D$ and also those who reported smoking on any of the previous four surveys. Although the questions used in the OAD screening questionnaire could possibly be more likely to pick up asthmatic patients rather than those with COPD, most patients with likely COPD should still have been identified for screening by their response to the smoking questions on the surveys between 1993 and 2001.

In the present study, 80 subjects had COPD (GOLD stage 2-4) confirmed by spirsmetryald d ho practice record of either asthmagr COHD, but 17 of these had received ind cled nedication in the past year. The failure to record either condition could have been due to bitheratelling, or diagnostic error, or bo (i). Af ur the 23 patients with COPD, confirmed by spirometry, had a practice record only of asthma, of whom 21 had received inhaled medication. In 14 patients there was a practice record of COPD but spirometric results were normal and the patients had no symptoms suggestive of COPD.

At the time of the study there was no universally accepted standard reversibility test or standardised dosing schedule for either salbutamol or antimuscarinic bronchodilators. The timing between dose administration and post-bronchodilator spirometry was adequate for the salbutamol dose but may not have been long enough to fully reverse bronchoconstriction in those subjects only sensitive to antimuscarinic agents. As this is uncommon, only a very small number of participants would have been affected in this way and a longer time interval may have had a wider negative impact on recruitment and cost of the study.

The unwillingness of patients to report symptoms may also have played a part in the apparent underdiagnosis of COPD in these practices, with patients accepting their symptoms as a part of ageing or being due to smoking, thus making them less likely to report symptoms to their doctor. This is supported by the relatively low response rate to 
the invitation to participate. Less than one third of those invited actually attended for spirometry and the possibility of selection bias must be considered. There were significantly more attenders than nonattenders with likely OAD which would tend to overestimate the prevalence of COPD-although more non-attenders than attenders smoked, which would lead to an underestimate. It is possible that the same factors lead to both a reluctance to report symptoms and a reluctance to participate in research regarding respiratory health.

The study was carried out in only two practice populations in one area in Manchester and may not be representative of the UK as a whole, although it is likely to represent areas with similar socioeconomic profiles. Comparison of these results with other reported studies is difficult due to wide variations in methods, definitions and populations sampled [22]. Although it is generally agreed that COPD is underdiagnosed and that perhaps only $25-50 \%$ of patients with the condition are known to their doctors $[2,8,23,24]$, little objective quantification has been undertaken and no figures from British general practice have been published. The present results show that their doctors knew about only $36.8 \%$ of subjects with a spirometric diagnosis of COPD, a similar proportion to a recent Swedish study [25].

The under-recording of COPD ientitied in this study cou'd hale inpletane implications in erms of missing opor curities to of er smoking cessation advice, with all the attendant morbidity, mortality and health care resource implications that this may have. The patients whose diagnoses have not been correctly recorded may also miss the opportunity to receive regular review of symptoms and therapy which may affect not only their symptoms but also their health-related quality of life.

The new UK General Practice GMS2 contract encourages correct diagnosis and follow-up of COPD by rewarding spirometry with investment. It remains to be seen if this system will help solve the problems of under-recording of COPD and access to spirometry.

\section{Conclusion}

There was an under-recording of COPD in these two practices. Whether this was due to under-reporting by patients, lack of (or faulty) diagnosis by the doctor, or administrative recording problems, it has important implications in terms of unmet need and utilisation of resources. It remains to be determined whether the recently introduced quality targets for diagnosing COPD in UK primary care will improve the situation.

\section{Confict of interests}

TF has received fees from GSK, Boehringer Ingelheim, Schering Plough and Astra Zeneca for speaking, funds for research from GSK, Boehringer Ingelheim, MSD and Schering Plough, funds for consultancy from GSK and Pharmacia and travel grants from GSK, Boehring ry rige bejim, Astra Zeneca, Chis:i f'ia rnate ueicals and MSD.

dilt ncore ceived a fee from Boehringer Ingelheim C.or speaking and trave grants from GSK, Boehringer Ingelheirnand.M:D.

M. nas received travel grants from GSK.

$\mathrm{PF}$ has received fees for attending symposia from GSK and MSD, funds for research from GSK, Boehringer Ingelheim and MSD and travel grants from GSK, Boehringer Ingelheim and MSD.

\section{Acknowledgments}

Funding: This study was funded by an unconditional grant from Boehringer Ingelheim.

Ethical Approval: South Manchester Local Research Ethics Committee approved this study. 


\section{Appendix A}

Please tick the appropriate box

1. What is your date of birth?

2. Are you

FEMALE

MALE

3. Have you had wheezing or whistling in your chest at any time in the last 12 months?

$$
\text { NO }
$$

YES

IF 'NO' GO TO QUESTION 4, IF 'YES':

3.1 Have you been at all breathless when the wheezing noise was present?

3.2 Have you had this wheezing or whistling when you did not have a cold?

4. Have you woken up with a feeling of tightness in your chest in the last $\mathbf{1 2}$ months?

5. Have you been woken by an attach of shortness of breath at any time in the last $\mathbf{1 2}$ months?

6. Have you woken by an attack of coughing at any time in the last 12 months?

7. Have you had an attack of asthma in the last 12 months?

8. Are you currently taking any medicine for asthma? (including inhalers, aerosols or tablets)

9. Has any person in your family (peirents grappparents, sisters, brothers or your child: $\in$ ) had asthma?

10. Have you ever hä hiay fever or eqzema?

11. How many cicareite jowou smoke each day?

12a. How many other adults live in your house?

$12 \mathrm{~b}$. How many of these adults smoke?

13. Do you usually cough first thing in the morning in the winter?

14. Do you usually cough during the day, or at night, in the winter?

IF 'NO' GO TO QUESTION 15, IF 'YES':

14.1 Do you cough like this on most days for as much as three months each year?

15. Do you usually bring up any phlegm from your chest first thing in the morning, in the winter?

16. Do you usually bring up any phlegm from your chest during the day, or at night in the winter?

IF 'NO' GO TO QUESTION 15, IF 'YES':

16.1 Do you bring up phlegm like this on most days for as much as three months each year?
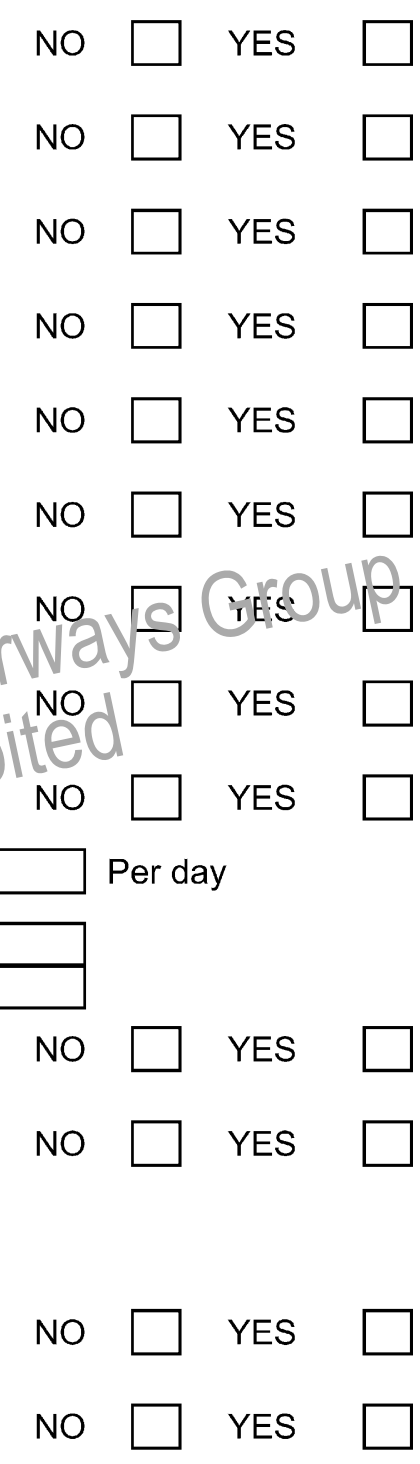

NO $\square$ YES

NO $\square$ YES 


\section{References}

[1] Murray CJ, Lopez AD. Mortality by cause for eight regions of the world: Global Burden of Disease Study. Lancet 1997;349(9061):1269-76.

[2] van den Boom G, van Schayck CP, van Mollen MP, et al. Active detection of chronic obstructive pulmonary disease and asthma in the general population. Results and economic consequences of the DIMCA program. Am J Respir Crit Care Med 1998;158(6):1730-8.

[3] European Respiratory Society: COPD [http://www.ersnet. org/ers/viewer_copd/mainFrame/default.aspx].

[4] American Thoracic Society: COPD [http://www.thoracic. org/COPD/1/points.asp].

[5] National Heart Lung and Blood Institute, World Health Organisation: Global Initiative for Chronic Obstructive Lung Disease (GOLD) (2003). Global Strategy for the Diagnosis, Management, and Prevention of Chronic Obstructive Pulmonary Disease [http://goldcopd.com/ download. asp?intld=231].

[6] van Weel C. Underdiagnosis of asthma and COPD: is the general practitioner to blame? Monaldi Arch Chest Dis 2002;57(1):65-8.

[7] Pena VS, Miravitlles M, Gabriel R, et al. Geographic variations in prevalence and underdiagnosis of COPD: results of the IBERPOC multicentre epidemiological study. Chest 2000;118(4):981-9.

[8] Takahashi T, Ichinose $M$, Inoue $H$, Shirato $K$, Hattori T, Takishima T. Underdiagnosis and undertreatment of COPD in primary care settings. Respirology 2003;8(4): 504-8.

[9] Manchester Health for All Working Party. In: Stevens R, editor. Health Inequalities and Manchester in the 199/'s Manchester: Manchester Health for All Working P or v 1993. pp. 14.

[10] Frank P, Ferry S, Morned T, Hannaford P. Use a postal cuestion naire to estimate the inely ur cerdiagnosis of as hma-like illness in a fuits. $3 r$ Gen Pract 1996;46(406):295-7.

[11] Frank PI, Morris JA, Frank TL, Hazell ML, Hirsch S. Trends in smoking habits: a longitudinal population study. Fam Pract 2004;21(1):33-8.

[12] Frank PI, Wicks PD, Hazell ML, et al. Temporal change in the prevalence of respiratory symptoms and obstructive airways disease 1993-2001. Br J Gen Pract 2005;55(517):596-602.

[13] Burney PG, Luczynska C, Chinn S, Jarvis D. The European Community Respiratory Health Survey. Eur Respir J 1994;7(5):954-60.

[14] Frank TL, Frank PI, Cropper JA, et al. Identification of adults with symptoms suggestive of obstructive airways disease: validation of a postal respiratory questionnaire. BMC Family Practice 2003;4(5).

[15] Gardner MJ, Altman DG. Confidence intervals rather than P values: estimation rather than hypothesis testing. $\mathrm{Br}$ Med J (Clin Res Ed) 1986;292(6522):746-50.

[16] Armitage P. Tests for linear trends in proportions and frequencies. Biometrics 1955;11(3):375-652.

[17] Butler D, Frost L, Morris J, Spence M, Stevens R, Young A. Health Inequalities and Manchester in the 1990s. Manchester: Manchester Health For All Working Party; 1993.

[18] Department of Planning Studies. 1998 Local Census Ward Comparison. Manchester: Manchester City Council; 2000.

[19] Office of National Statistics: Neighbourhood Statistics [http://www.statistics.gov.uk/neighbourhood/metadata. asp?dsno=21]

[20] Lindstrom M, Jonsson E, Larsson K, Lundback B. Underdiagnosis of chronic obstructive pulmonary disease in Northern Sweden. Int J Tuberc Lung Dis 2002;6(1):76-84.

[21] National Collaborating Centre for Chronic Conditions. Chronic obstructive pulmonary disease. National clinical guideline on management of chronic obstructive pulmonary disease in adults in primary and secondary care. Thorax 2004;59(Suppl 1):1-232.

[22] Halbert RJ, Isonaka S, EEPIg DD, labul A. interpreting COPD prevalence esil inctes. What is the true burden of disease? Chest (2) $03 ; 123(5): 1684-92$.

1237 van Schayck CP, Charianies NH. Detection of asthma and

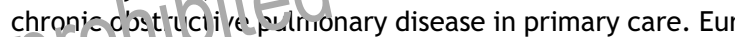
Hes $\mathrm{F}$ ir 1 2003;39(Supplement):16s-22s.

[24] Nclvor RA, Tashkin DP. Underdiagnosis of chronic obstructive pulmonary disease: a rationale for spirometry as a screening tool. Can Respir J 2001;8(3):153-8.

[25] Lundbäck $B$, Lindberg $A$, Lindstrom $M$, et al. Obstructive Lung Disease in Northern Sweden S: Not 15 but $50 \%$ of smokers develop COPD?-Report from the Obstructive Lung Disease in Northern Sweden Studies. Respir Med 2003;97(2):115-22.

Available online at www.sciencedirect.com 